\title{
БАГАТОВИМІРНИЙ НЕО-ФАЗЗІ НЕЙРОН У МЕДИЧНОМУ ДІАГНОСТУВАННІ ХВОРОБ ЩИТОВИДНОї ЗАЛОЗИ
}

\author{
Перова І.Г., доц. к.т.н. \\ rikywenok@gmail.com \\ Мірошниченко Н.С., студент \\ nellymiroshnichenko@mail.ru \\ Факультет електронної та біомедичної інженерії \\ Харківський національний університет радіоелектроніки \\ м. Харків, Україна
}

\begin{abstract}
Реферат - В роботі проведено вибір типу нейро-фаззі мереж та можливостей їхнього використання для діагностування захворювань щитовидної залози: гіпертиреозу, гіпотиреозу та еутиреозу. Проведено вибір та удосконалення алгоритму навчання багатовимірного нео-фаззі нейрону та апробацію його роботи на клінічних медичних даних. Створено нативний додаток, який уможливлює використання багатовимірного нео-фаззі нейрону для завдань медичного діагностування із розрахунком помилки при навчанні та тестування і візуалізачією медичних даних для кращого сприйняття інформації лікарем.
\end{abstract}

Ключові слова - щзитоподібна залоза, нео-фаззі нейрон, гіпертиреоз, медичні дані, гіпотиреоз, еутиреоз, синаптичні ваги.

\section{I. ВСТУП}

Інтелектуальний аналіз даних — це виявлення прихованих закономірностей або взаємозв'язків між змінними у великих массивах необроблених даних.

Важливо застосовувати нові методи діагностування на основі систем прийняття рішення. Так як дані системи мають велику кількість переваг: оперують зі слабкоструктурованими рішеннями, можуть бути пристосовані для групового та індивідуального використання, підтримують як взаємозалежні, так і послідовні рішення, підтримують три фази процесу рішення: інтелектуальну частину, проектування та вибір, є гнучкими і адаптуються до змін як організації, так і свого середовища, підвищують ефективність процесу прийняття рішеня [1].

У ситуаціях, коли заздалегідь не відомо взаємне розташування кластерів, що відповідають за різні захворювання, рівень їх перекриття, а також коли заздалегідь не відомо кількість пацієнтів у вибірці даних, можна скористатися підходами, що забезпечують нечіткий розподіл пацієнтів на групи-діагнози. Одним 3 таких підходів $є$ використання багатовимірного нео-фаззі нейрона.

\section{II. МЕТА ДОСЛІДЖЕННЯ}

Дослідження та застосування для інтелектуального аналізу даних методів теорії штучних нейронних мереж, а саме нео-фаззі мережі, що складається 3 багатовимірного нео-фаззі нейрону.

Проведення огляду публікацій останніх років за тематикою виявлення захворювань щитовидної залози на основі систем прийняття рішень.

Розподілення реальних медичних даних на діагнози для кожного з пацієнтів та розрахунок відсотку помилки при навчанні системи та при іï тестуванні.

\section{III. МАТЕРІАЛИ ДОСЛІДЖЕНЬ}

Для проведення дослідження спочатку були отримані медичні картки пацієнтів, які треба було опрацювати, і по даним, які нам вдалося вилучити, ті які були найбільш інформативними, скласти систематизовану таблицю. В даній таблиці дані задані числовими значеннями.

Формуючи таблицю, деякі дані містили пропуски, це обумовлено тим, що не у всіх пацієнтів $є$ ті чи інші ознаки. Щоб уникнути пропусків в таблиці, слід або 
зовсім вилучити з експерименту людину, яка не має всіх значень, або заповнити пропуски власноруч. У роботі використано другий спосіб, заповнення всіх пропусків власноруч, тим самим зберігши кількість пацієнтів, які приймали участь у досліді.

Пропуски заповнені за допомогою методу нечіткої просторової екстраполяції.

Даний метод допомагає розрахувати відстань між пацієнтом з пропуском у даних та іншими пацієнтами, у ознаках яких не містяться пропуски. Отримати відстань.

Наступним кроком визначити приналежність (ступінь схожості) пацієнта 3 пропуском у даних до інших пацієнтів, як функцію, обернену до відстані. Та здійснити заповнення у пропуску даних.

Отримавши таблицю вже 3 заповненими пропусками, розпочинається навчання нео-фаззі мережі.

На ii входи подаються ознаки в кількості 9, до яких відносились інформативні дані, такі як вік пацієнта та його гендерна приналежність, а також значення показників гормонального дослідження аналізу крові: тиреотропіну (ТТГ), тироксину вільного (Т4віл) та тироксину загального (Т4 заг), трийодтироніну вільного (Т3віл) та трийодтироніну загального (ТЗзаг), а також аутоантитіл до тиреопероксидази (АТ к ТПО) та аутоантитіл до тиреоглобуліну (АТ к ТГ) для 116 пацієнтів, форма 027/о.

В якості діагнозів було обрано три хвороби щитовидної залози: гіпотиреоз, гіпертиреоз та еутиреоз [2].

Гіпертиреоз - захворювання, пов'язане 3 підвищеною активністю щитовидної залози і надлишком вироблених нею гормонів (рис.1). При даному захворюванні в кров надходить більша, ніж необхідна кількість гормонів, що виробляються щитовидною залозою, і в кілька разів зростає інтенсивність обміну речовин в організмі. Найчастіше гіпертиреоз спостерігається у жінок у віці від двадцяти до сорока років, хоча 3 ним можуть зіткнутися і чоловіки в будь-якому віці [3].

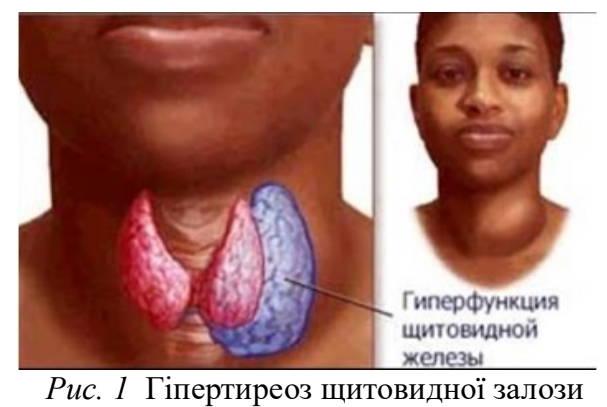

Гіпотиреоз - захворювання, яке виникає через нестачу йоду в організмі (рис.2). Дефіцит йоду в організмі призводить до того, що щитовидна залоза починає виробляти недостатню кількість гормонів, необхідних для нормальної роботи організму і обміну речовин [4].



ГИПОТИРЕОЗ



HOPMA
Puc. 2 Гіпотиреоз щитовидної залози

Щоб зловити з крові ті нечисленні крихти йоду, щитовидна залоза починає рости, збільшуватися в розмірі і в людини поступово виростає зоб. Якщо вчасно не забезпечити допомогу, то зоб може досягти ваги в кілька кілограм, у той час, коли нормальна вага щитовидної залози становить 25-30 грамів [5].

Еутиреоз - це захворювання щитовидної залози, при якому вона хоч i виробляє необхідну кількість гормонів, але при першому ж перепаді гормонального фону щитовидна залоза збільшується i 3'являється вузловий зоб (рис.3) [6].

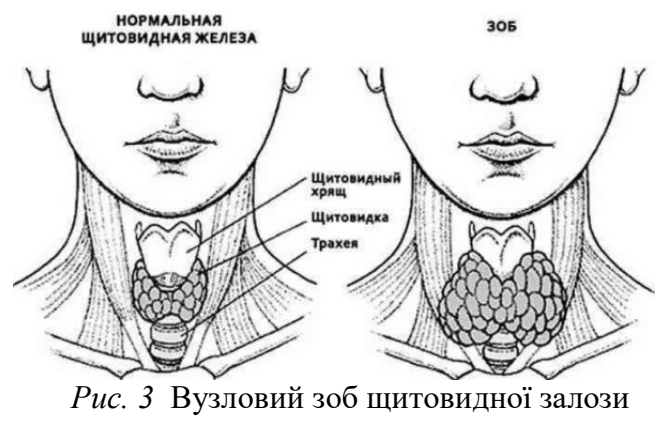


Еутиреоз одне із захворювань, яке дуже складно виявити і воно відноситься до небезпечних захворювань, так як впливає на роботу всього організму [7].

\section{IV. РЕЗУЛЬТАТИ ТА ОБГОВОРЕННЯ}

Перед тим як обрати підхід та метод діагностування щитовидної залози, було оглянуто класичні підходи до діагностування захворювань щитовидної залози.

Одним 3 таких підходів $\epsilon$ метод класифікації на основі класифікації Байеса. Michael L. Raymer представив алгоритм на основі класифікації Байєса, який демонструє покращену здатність усунення невірних функцій 3 великих наборів даних, допомагаючи дослідникам ідентифікувати ті функції, які пов'язані 3 конкретною досліджуваною проблемою. Ефективність цієї методики для вибору і вилучення ознак демонструється на декількох біологічних i медичних наборах даних, а саме на даних щитовидної залози

Ще одним 3 підходів $\epsilon$ метод класифікації 3 використанням алгоритмів вибору ознак на основі фільтра (F-Score) i обгортки (Recursive Feature Elimination) [8]. A.T Azar, A.E. Hassanien, T. Kim вважають, що правильна i рання діагностика захворювань $є$ важливою і обов'язковою в галузі охорони здоров'я для правильного і своєчасного лікування. Цей факт $є$ найбільш важливим при таких захворюваннях, як щитовидна залоза, яку дуже важко виявити, тому що іiі симптоми збігаються 3 кількома захворюваннями. В своїй роботі вони використали алгоритми машинного навчання для діагностики захворювань щитовидної залози. Типова система діагностики захворювань щитовидної залози використовує три основні етапи, а саме: вилучення ознак, вибір ознак i класифікацію. Основною метою їх роботи $є$ аналіз використання алгоритмів вибору ознак на основі фільтра (F-Score) і обгортки (Recursive Feature Elimination) та його вплив на ідентифікацію та класифікацію захворювань. Аналіз виконаний 3 алгоритмами зменшення розмірності компонентного аналізу принципу. Оцінка ефективності проводилася 3 трьома метриками: точність, чутливість i специфічність. Для аналізу обраних алгоритмів були використані чотири класифікатора: багатошаровий Персептрон, Нейронна мережа зворотного поширення, машина опорного вектора i машина екстремального навчання. Експериментальні результати показали, що в той час як усунення F-балів i рекурсивних ознак поліпшило результати діагностики захворювань щитовидної залози, алгоритм, заснований на оболонці, дав максимальну ефективність і справив максимальну точність 98,14\% до класифікатора ELM [9].

Зробивши огляд існуючих методів діагностування захворювань щитовидної залози, був обраний власний метод діагностування. Так як розглянуті, вже існуючі методи не забезпечують роботу системи в онлайн режимі.

В якості системи для діагностування захворювань щитовидної залози було обрано багатовимірний нео-фаззі нейрон (рис.4) [10].

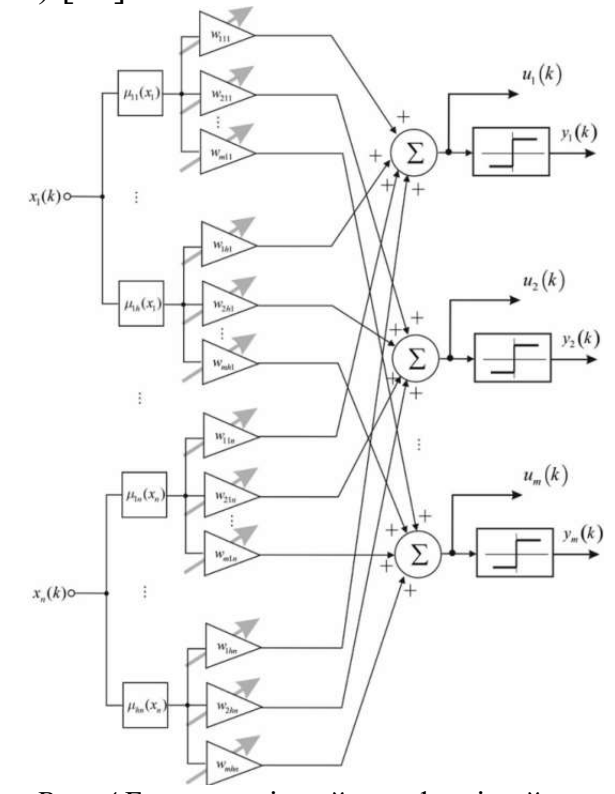

Puc. 4 Багатовимірний нео-фаззі нейрон

Автори нео-фаззі-нейрона для фазифікації вхідних даних використовували традиційні трикутні конструкції, які відповідають умовам розбиття Руспіні: 


$$
\left\{\begin{array}{c}
\frac{x_{i}-c_{i, j}-1}{c_{i j}-c_{i}, j-1} \text { якщо } x_{i} \mid \in\left[c_{i}, j-1, c_{i j}\right] ; \\
\frac{c_{i, j}+1-x_{i}}{c_{i}, j+1-c_{i j}}, \text { якщо } x_{i} \mid \in\left[c_{i j}, c_{i}, j+1\right] \\
0, y \text { протилежному випадку. }
\end{array}\right.
$$

де $c i j$ - обрані досить випадково (зазвичай рівно розподілені) параметри центрів функцій належності на інтервалі $[0,1]$, де $0 \leq$ $x i \leq 1$. Такий вибір функцій належності гарантує, що вхідний сигнал $x i$ активує тільки дві сусідні функції, а їх сума буде завжди рівною одиниці.

Відзначимо, що трикутні функції належності забезпечують кусково-лінійну апроксимацію, яка призводить до погіршення точності результатів. 3 метою мінімізації цього ефекту можна збільшити кількість синаптичних ваг i, таким чином, значно ускладнити архітектуру і алгоритм навчання [11].

Кубічні сплайни можна використати як функції належності, аби позбутися вищезазначених проблем:

$$
\mu_{i j}\left(x_{i}\right)=\left\{\begin{array}{l}
0,25\left(2+3 \frac{2 x_{i}-c_{i j}-c_{i, j-1}}{c_{i j}-c_{i, j-1}}-\left(\frac{2 x_{i}-c_{i j}-c_{i, j-1}}{c_{i j}-c_{i, j-1}}\right)^{3}\right), x \in\left[c_{i, j-1}, c_{i j}\right] ; \\
0,25\left(2-3 \frac{2 x_{i}-c_{i, j+1}-c_{i j}}{c_{i, j+1}-c_{i j}}+\left(\frac{2 x_{i}-c_{i, j+1}-c_{i j}}{c_{i, j+1}-c_{i j}}\right)^{3}\right), x \in\left(c_{i j}, c_{i, j+1}\right] ; \\
0, \quad \text { у протилежноку випанку. }
\end{array}\right.
$$

Початкові дані були розподіленні на навчальну і тестову частини.

Пронормований та закодований вектор вхідних ознак вигляду $x(k)=$ $\left(x_{1}(k), x_{2}(k), \ldots x_{n}(k)\right)^{T}$ надходить на вхід багатовимірного нео-фаззі нейрону. При надходженні вектор стовпця вхідних ознак кожного пацієнта в кількості $n$, що в даній системі дорівнюе 9, подається до однотипних нелінійних синапсів нео-фаззінейронів, кожен нейрон яких генерує на виході сигнал $\hat{\mathrm{x}}_{d}(k), d=1,2, \ldots, m$. У результаті компоненти векору виходів

$$
\hat{x}(k)=\left(\hat{x}_{1}(k), \hat{x}_{2}(k), \ldots \hat{x}_{m}(k)\right)^{T}
$$

обчислюються незалежно.

Система має 4 виходи, так як може прийняти значення: 1-гіпотериоз, та буде закодована 0001; 2-гіпертиреоз - 0010; 3умовно здоровмй пацієнт - 0100; 4-еутеріоз -1000 .
Далі обчислені значення потрапляють на синаптичні ваги, значення яких на першому кроці задано випадковим чином [12].

Вектори поточних значень рівнів належності i значення синаптичних ваг перемножуються та формують аналоговий вихід системи. Щоб отримати більш точні результати, мережа повинна краще налаштовувати синаптичні ваги. У якості процедури налаштування синаптичних ваг, можна записати багатовимірну модифікацію алгоритму Уидроу-Хоффа:

$$
\left\{\begin{array}{l}
W(k+1)=W(k)+r^{-1}(k)(d(k)-W(k) \mu(k)) \mu^{T}(k),(3) \\
r(k)=\alpha r^{-1}(k-1)+\|\mu(k)\|^{2}, \quad 0 \leq \alpha \leq 1 .
\end{array}\right.
$$

Ця процедура $є$ рекурентною, тобто надає можливість обробляти медичні дані послідовно. Також ця процедура $\epsilon$ градієнтною, тобто вона забезпечує велику швидкодію [13].

Звівши сигнал помилки до мінімального значення, отримуємо результат роботи мережі у відсотках, при навчанні мережі і при тестуванні. Відсоток помилки при навчанні нео-фаззі нейрону на медичних даних захворювань щитовидної залози склав 2,60\%, а при тестуванні 3,63\%. Після цього нео-фаззі нейрон вважається навченим та за допомогою нього стає можливим проведення медичного діагностування.

Для розширення можливостей діагностування був створений нативний додаток Neo. Вiн був створений за допомогою фреймворка Electron. Electron це фреймворк для створення нативних додатків за допомогою таких технологій як: JavaScript та HTML, CSS.

Вхідною точкою $\epsilon$ основний файл визначений в файлі package.json, саме він i виконується, коли розпочинає роботу наша програма. У цьому основному файлі (який зазвичай називається main) створюються вікна програми.

Оскільки нейронна мережа написана на Python використовуємо бібліотеку pythonshell для взаємодії 3 нею. Ця бібліотека дозволяе запускати Python скрипти 3 Node.js. Додаток має інтерфейс, за допомогою якого можемо завантажити файл 
3 медичними даними (рис.5), після завантаження файлу, дані будуть відображенними в таблиці на екрані, також буде відображено два поля для введення даних.

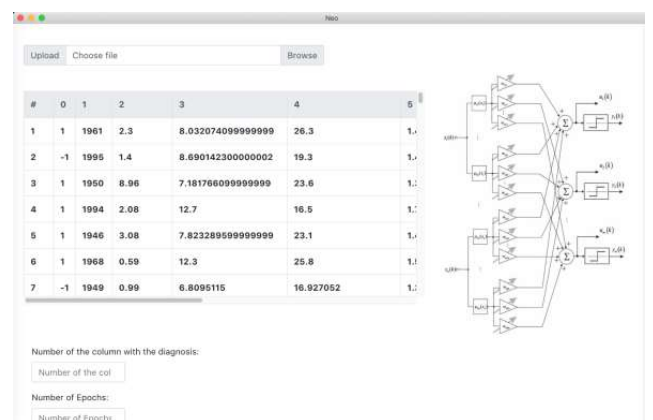

Puc.5 Вікно веб-додатку

В перше поле (Number of column with the diagnosis) потрібно внести номер колонки, в якій міститься інформація про діагноз пацієнтів для подального навчання нео-фаззі нейрону. В друге поле (Numbero fEpochs) необхідно внести кількість епох навчання нео-фаззі нейрону, тобто кількість разів повторення процесу навчання. Після вводу даних, можна розпочати навчання мережі, натиснувши на кнопку To Train, після закінчення навчання можна побачити відсоток помилки навчання (він буде відображений поряд 3 кнопкою) після навчання мережу можна протестувати, також натиснувши на кнопку Test, відсоток помилки тестування буде відображено поряд 3 кнопкою, також для наочності буде відображена діаграма розкиду (рис.6), тобто візуалізація даних в просторі перших трьох головних компонент.

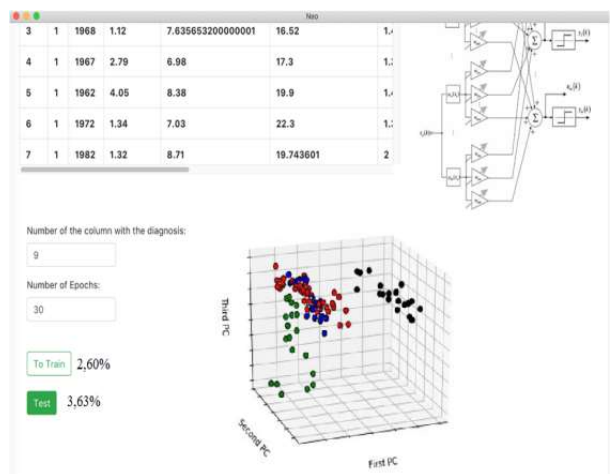

Puc. 6 Вікно нативного додатку

\section{V. ВИСНОВКИ}

1. Проведено огляд класичних підходів до діагностування захворювань щитовидної залози.

2. Обрано тип нейро-фаззі мережі для діагностування гіпертиреозу, гіпотиреозу та еутиреозу.

3. Проведено вибір та модифікацію алгоритму навчання багатовимірного неофаззі нейрону.

4. Проведено апробацію роботи багатовимірного нео-фаззі нейрону на клінічних даних пацієнтів із захворюваннями щитовидної залози. Відсоток помилки при навчанні склав $2,60 \%$, а при тестуванні $3,63 \%$.

\section{ПЕРЕЛІК ПОСИЛАНЬ}

[1]Kountchev R. Advancesin Intelligent Analysis of Medical Data and Decision Support Systems (Studiesin Computational Intelligence) / Kountchev R. andetc - Springer. - 2013. - 246 p. [2] Волкова Н.П. Щитовидная железа / Н.П. Волкова М.: Эксмо, 2016. - 127 с.

[3] Генри М. Заболевания щитовидной железы / М. Генри, Кроненберг и др. - М.: РидЭлсивер, 2010. - 392 с.

[4] Петунина Н. А. Болезни щитовидной железы / Н.А Петунина, Л.В. Трухина. - М.: ГЭОТАР-Медиа, 2011. - 222 с.

[5] Пинский С. Б. Диагностика заболеваний щитовидной железы / С.Б. Пинский, А.П. Калинин, В.А. Белобородов. Л.: Медицина, 2005. - 192 с.

[6] Казьмин В.Д. Болезни щитовидной и около щитовидной желез / В.Д. Казьмин. - М.:Феникс, 2009. - 256 с.

[7] Холмогоров, В. В. Все о заболеваниях щитовидной железы и ее лечении / В.В. Холмогоров. - М.:Феникс, 2008. $-192 \mathrm{c}$.

[8]Michael L. Raymer Knowledge discovery in medical and biological datesets using a hvbrid Baves classifier evolutionarv algorithm / Michael L. Raymer, Travis E. Doom, Leslie A. Kuhn, William F. Punch - 2003. - 54 p.

[9] Azar A.T. Expert system based on neural fuzzy rules for thyroid diseases diagnosis / A.T Azar , A.E. Hassanien, T. Kim // Computer Science Artificial Intelligence. - 2012. - 1-12 p.

[10] Мирошниченко Н.С., Перова И.Г. Медицинское диагностирование на основе нейросетевых технологий/ Н.С Мирошниченко, И.Г. Перова, // Прикладная радиоэлектроника: науч.-техн. журнал. -2017 . Том 16. № 1. - C. 46-50.

[11] Тищенко А.К. Прогнозуюча нейрон-фаззі мережа на основі багатовимірного нео-файззі нейрона та iï процедура навчання / А.К. Тищенко, І.П. Плісс, К.О. Шкурко // Радіоелектроніка, інформатика, управління. - 2014. №2. C. $120-125$.

[12] Mulesa P. Fuzzy Spacial Extrapolation Method Using Manhattan Metrics for Tasks of Medical Data Mining Computer Science and Information Technologies / P. Mulesa, I.Perova - Lviv, Ukraine. - 2015 - P. 104-106

[13] Мірошниченко Н.С. Медицинское диагностирование сердечно-сосудистых заболеваний при помощи нейрофаззисистемы / Н.C. Мірошниченко // ISM-2018 «Інформаційні системи та технології в медицині». - 2018. $179 \mathrm{c}$. 
УДК 612.825.1

\title{
МНОГОМЕРНЫЙ НЕО-ФАЗЗИ НЕЙРОН В МЕДИЦИНСКОМ ДИАГНОСТИРОВАНИИ БОЛЕЗНЕЙ ЩИТОВИДНОЙ ЖЕЛЕЗЫ
}

\author{
Перова И.Г., доц. к.т.н. \\ rikywenok@gmail.com \\ Мирошниченко Н.С., студент \\ nellymiroshnichenko@mail.ru \\ Факультет электронной и биомедицинской инженерии \\ Харьковский национальный університет радиоэлектроники \\ г. Харьков, Украина
}

Реферат - В работе проведен выбор типа нейро-фаззи сетей и возможностей их использования для диагностики заболеваний щитовидной железы гипертиреоза, гипотиреоза и эутиреоза. Проведен выбор и усовершенствование алгоритма обучения многомерного нео-фаззи нейрона и апробация его работы на клинических медичинских данных. Создано приложение, которое делает возможным использование многомерного нео-фаззи нейрона для задач медицинского диагностирования с расчетом ошибки при обучении и тестировании и визуализаџией медицинских данных для лучшего восприятия информаџи врачом.

Ключевые слова - щчитовидная железа, нео-фаззи нейрон, гипертиреоз, медицинские данные, гипотиреоз, эутиреоз, синаптические веса.

UDC 612.825.1

\section{MULTIDIMENSIONAL NEO-FUZZY NEURON IN THE MEDICAL DIAGNOSIS OF THYROID DISEASE}

Perova I., Assoc. Ph.D. rikywenok@gmail.com Miroshnichenko N., student nellymiroshnichenko@mail.ru Faculty of Electronic and Biomedical Engineering Kharkiv National University of Radio Electronics, Kharkiv, Ukraine

Abstract - In the work, the type of neuro-fuzzy networks and the possibilities of the it use for the diagnosis of thyroidd is eases, hyperthyroidism, hypothyroidism and euthyroidism were selected. The selection and improvement of the learning algorithm for the multidimensional neo-fuzzy neuron and the testing of its work on clinical medical data were carriedout. A native application has been created that makes it possible to use a multidimensional neo-fuzzy neuron for medical diagnostic tasks with the calculation of errors in training and testing and the visualization of medical data for a better perception of information by a doctor.

Keywords - thyroid, neo-fuzzy neuron, hyperthyroidism, medical data, hypothyroidism, euthyroidism, synaptic weights. 